\title{
STUDY OF ACID-BASE BALANCE IN OPEN-HEART SURGICAL PATIENTS
}

\author{
W. A. Dodds, M.D., ${ }^{*}$ ANd E. G. Forseng, M.D. ${ }^{\dagger}$
}

ACID-BASE DERANGEMENTS are frequently encountered in surgical patients, preoperatively, during the surgical procedure, and postoperatively. For some time surgeons and anaesthetists have concerned themselves with the control of these changes, and more recently the postoperative period has come under close scrutiny as regards acidosis and decreased arterial saturation.1,2 The advent of open-heart surgery by means of a total cardiopulmonary by-pass, on patients with abnormal cardiovascular physiology subjected to artificial haemodynamic control, has resulted in tremendous experimental and clinical activity towards a better understanding and control of acid-base status. ${ }^{3,4,5}$

During the past five years nearly 500 patients have undergone cardiopulmonary by-pass at the Vancouver General Hospital using the Lillehei-DeWall bubble-type oxygenator $^{6}$ and more recently a modification of the Gross disk-type oxygenator. ${ }^{7}$ Control of these patients has been maintained by monitoring the direct arterial and venous pressures, the electrocardiogram, the electroencephalogram, arterial and venous oxygen saturations, and the arterial and venous $\mathrm{pH}$. By these means a reasonably satisfactory knowledge of the patient's condition has been available at all times.

Extracorporeal circulation methods in the future will undoubtedly improve. However, at this stage we feel that the maintenance of high standard perfusion is aided by the continuance of our monitoring control. Recently, our interest has centred around more particular control of acid-base balance from both the respiratory and metabolic aspect. Although of some value in our earlier cases the $\mathrm{pH}$ of the blood alone was found to be inadequate in assessing the respiratory and metabolic components of the operative and postoperative acid-base balance.

During the past one and one-half years we have undertaken a comprehensive study of the over-all acid-base changes in 150 clinical open-heart cases. For this study we have chosen to use the Astrup micro-apparatus. ${ }^{8,9,10}$ This instrument was selected because of the rapidity with which samples could be analysed and also because of its temperature-compensating mechanism; all readings were taken at $38^{\circ} \mathrm{C}$. The apparatus also has the additional advantage of requiring a minute quantity of blood, such as can be obtained from a finger-prick; yet it provides values comparable with those from an arterial blood sample in the majority of circumstances. ${ }^{11}$ We have found that the frequent monitoring of the individual patient as regards $\mathrm{pCO}_{2}$, arterial $\mathrm{pH}$, base excess, and standard bicarbonate according to the Astrup nomogram ${ }^{12}$ has considerably improved our handling of these cases.

\footnotetext{
"Clinical Assistant Professor, Surgery, Division of Anaesthesia, University of British Columbia Medical Faculty, Vancouver General Hospital, Vancouver, British Columbia.

$\grave{i}$ National Heart Research Fellow, University of British Columbia Medical Faculty, Vancouver General Hospital.
} 
The Astrup nomogram is suitable for the calculation of all relevant acid-base values of blood. The nomogram uses a $\mathrm{pH} / \log \mathrm{pCO}_{2}$ co-ordinate system as the relation between $\mathrm{pH}$ and $\log \mathrm{pCO}_{2}$ is approximately rectilinear. Two superimposed curves permit direct reading of the buffer base and base excess of a blood sample after equilibration with two known $\mathrm{CO}_{2}$ tensions. The term "buffer base", refers to the sum of buffer anions (mainly bicarbonate and proteinate) in the blood. "Base excess" is a direct measure of the amount of exces\$ acid or base present in the blood sample expressed in $\mathrm{mEq}$. per litre. A positive base excess value indicates the presence of a metabolic alkalosis, while a negative value indicates the presence of a metabolic acidosis. The buffer base and base excess values also provide a convenient means of checking the accuracy of the results in that buffer base minus base excess must equal the actual haemoglobin content of the blood sample plus or minus 2 grams-\%. $\%{ }^{12}$

The base excess curve of the nomogram provides a figure from which the quantity of bicarbonate required to neutralize the patient's extracellular fluid volume may be calculated, using the sconvenient formula of Mellemgaard and Astrup; i.e. base excess $\times 0.3 \times$ wt. in kg. $=\mathrm{NaHCO}_{3}$ required for stabilization, expressed in mEq. ${ }^{9}$ The standard bicarbonate, which differs from the actual bicarbonate in that it does not depend on the $\mathrm{pCO}_{2}$ and thus expresses metabolic changes in isolation, may also be read from the nomogram. Therefore, the metabolic component of the acid-base balance may be expressed in three ways-buffer base, base excess, and standard bicarbonate. The $\mathrm{pCO}_{2}$ may be calculated from the nomogram after measurement of the actual $\mathrm{pH}$ and the $\mathrm{pH}$ after equilibration with $\mathrm{CO}_{2}$ at two known tensions, or at one known tension when the haemoglobin concentration is known. The $\mathrm{pCO}_{2}$ is a measure of the respiratory acid-base disturbance. In this manner the respiratory and metabolic components of the acid-base balance may be calculated and illustrated separately.

\section{METHOD}

In order to establish a routine method for the assessment of these cases it was decided that samples should be done on a time and procedural basis. Under this scheme blood is drawn for acid-base studies one or two days before surgery, before and just after the induction of anaesthesia, and then every twenty minutes during the operative procedure. Two additional samples are taken to bracket the onset and end of the by-pass portion of the operation. These studies are continued into the postoperative period until the patient's acid-base metabolism is stable. On the strength of the results obtained, definitive corrective treatment is instituted.

To establish the normal pattern produced by anaesthesia and surgery, several patients were studied when by-pass was not a part of the procedure. The graph shown in Figure 1 was obtained by following a 4-year-old patient undergoing correction of coarctation of the aorta. This patient not only required no by-pass but also was left with normal cardiovascular physiology postoperatively. On the day before surgery the $\mathrm{pH}, \mathrm{pCO}_{2}$, and base excess values were within normal range, as shown at point 1 . After a light premedication on the day of surgery the preoperative excitement produced a degree of respiratory alkalosis (point 2). 


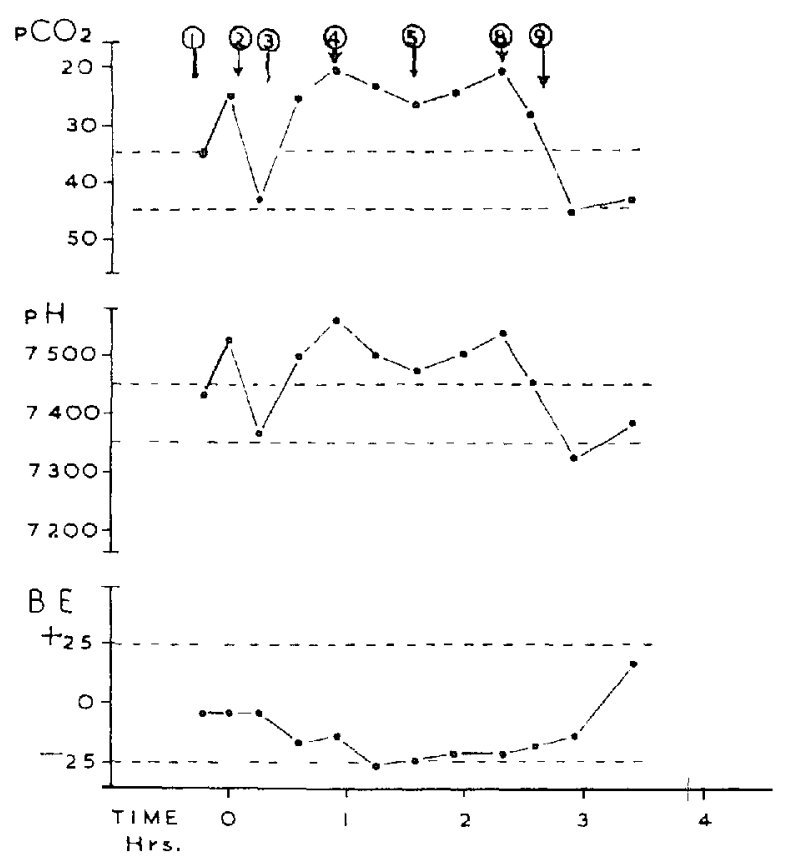

Figure 1. Coarctation of aorta: R.W. 4/2 years.

During induction of anaesthesia and intubation these values fell to normal (point 3). The controlled respiration necessary, during thoracotomy and because of the light intravenous anaesthetic agents used, produced a marked respiratory alkalosis and a mild compensatory metabolic acidosis during the surgery (point 4). There is some lessening of the respiratory alkalosis as the surgeon packs off the lungs to expose the operative site (point 5). As spontaneous respirations are re-established and the patient extubated and returned to the recovery room, all values return to normal (points 8 and 9). This graph was found to be characteristic, with minor deviations, of all patients for whom a by-pass was not used, and who were studied in this manner.

To this so-called normal or characteristic pattern we now add a period of cardiopulmonary by-pass. The graph shown in Figure 2 , was obtained by following a patient 18 years of age who was undergoing correction of a valvular pulmonary stenosis. The patient was almost symptom-free and presented with a mild degree of respiratory alkalosis. The curves shown closely follow our control graph, including the pumping period (points, 6-7). The decrease in alkalosis on initiating by-pass was probably due to the acidity of the stored blood from the oxygenator. ${ }^{13}$

The graph shown in Figure 3 was obtained by following a 20-year-old patient operated on to correct a mitral regurgitation. This graph also closely follows the control, with some increased respiratory acidosis as the patient is returned to the recovery room. Therefore, we conclude that the introduction of cardiopulmonary by-pass alone does not markedly: alter the acid-base status of the patient.

\section{Results}

The following of our patients in this comprehensive manner has led to the establishment of a normal pattern as the patient responds to anaesthesia, surgery, 
DODDS \& FORSENG: ACID-BASE BALANCE IN OPEN-HEART SUURERY

\section{PULMONARY STENOSIS}

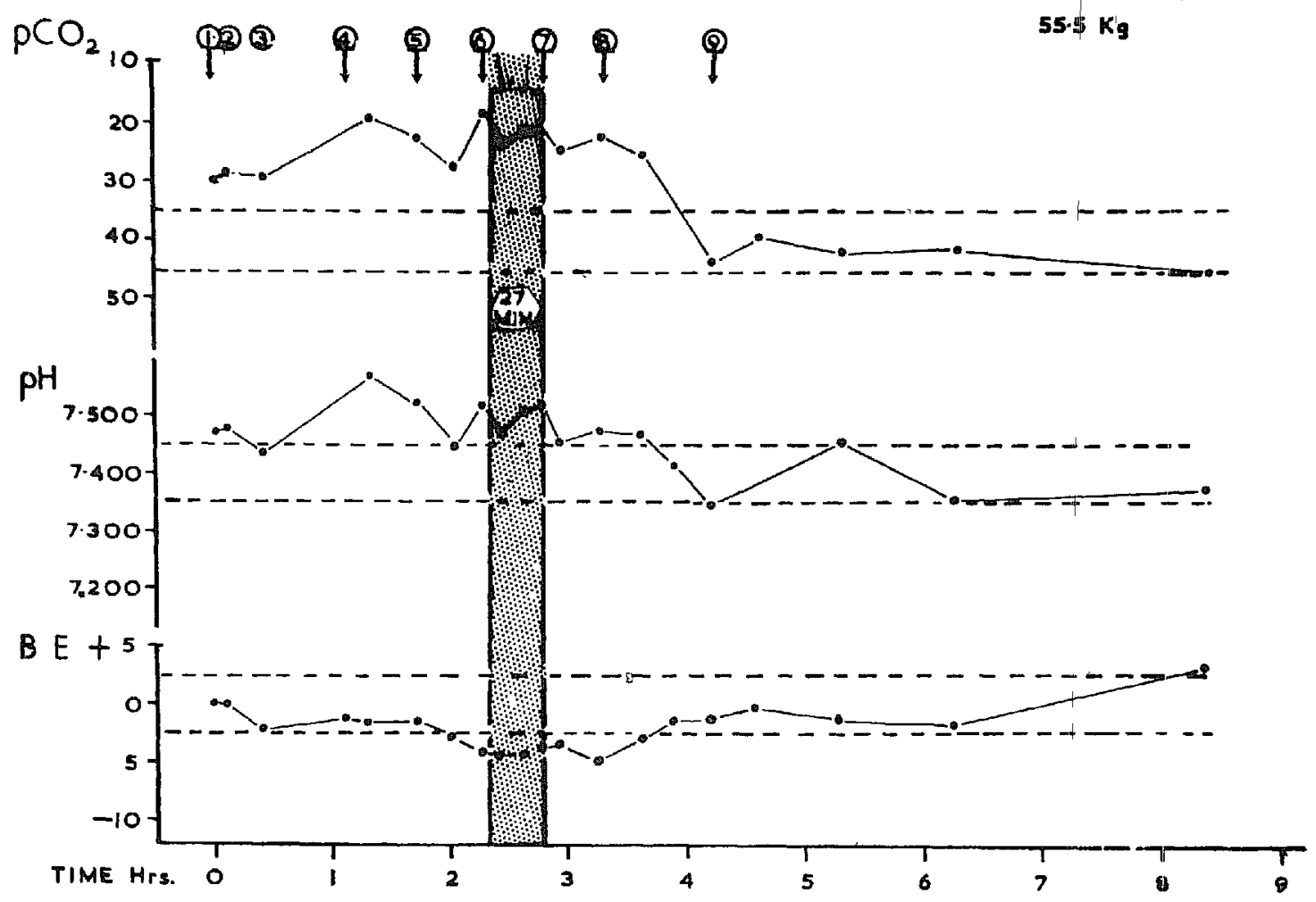

FigURE 2

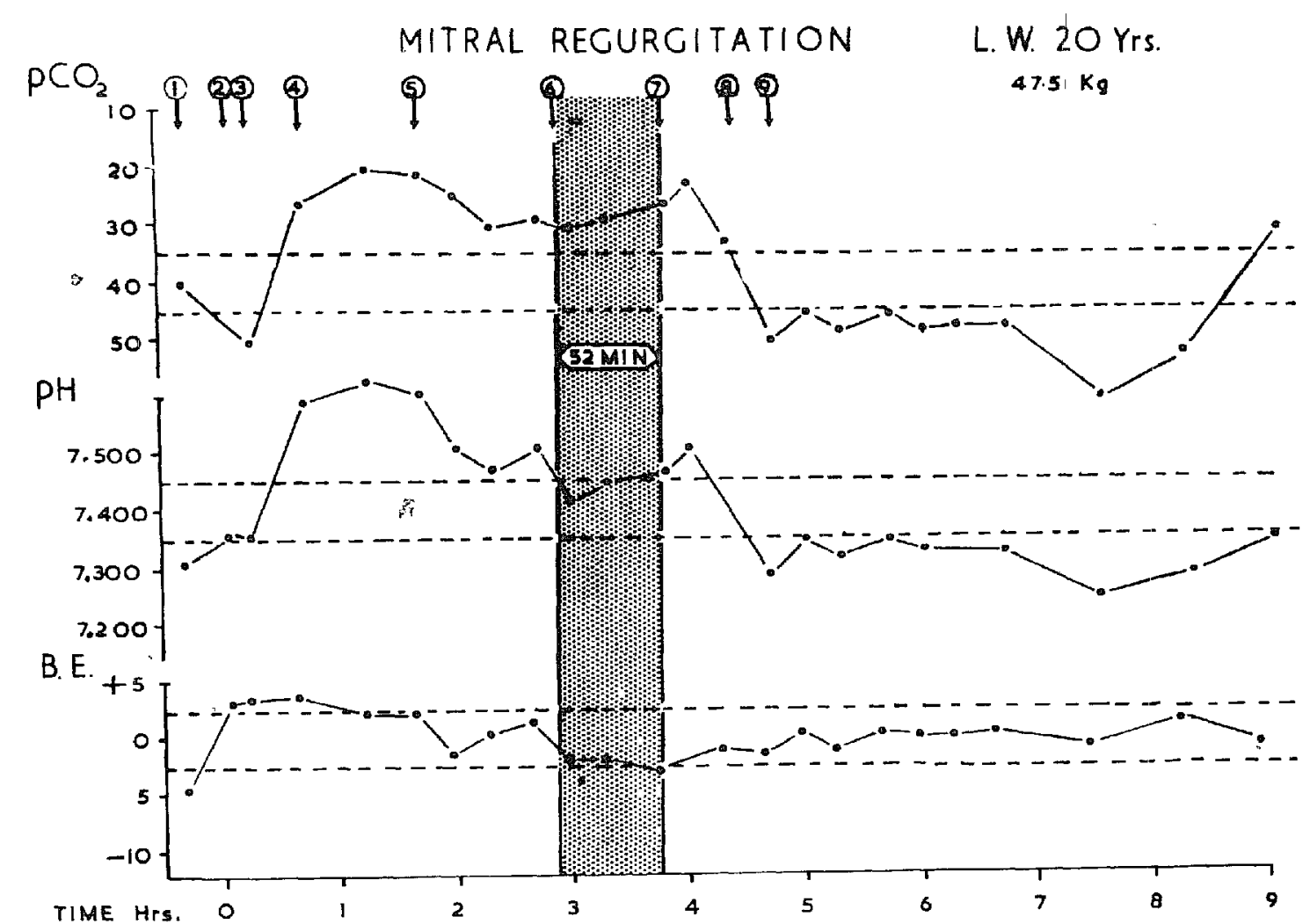

Figure 3 
and perfusion. There have been, however, many variations from this normal pattern in our study because of the many variables that occur. Such variables are: the type of lesions, which may be congenital or acquired, severe or moderate; the age, ranging from 6 weeks to 60 years, the position of the patient on the table and the surgical approach; the length and adequacy of perfusion; the use of varying degrees of hypothermia, the adequacy of surgical correction; the development of postoperative complications; and the emotional reaction of the patient. Because of these variables statistical analyses of the results obtained are most difficult to assess. However, careful monitoring of the acid-base status in our patients has allowed for early correction of deviations from the normal in $(a)$ the respiratory component, by increasing alveolar ventilation or pulmonary flow if necessary, and $(b)$ the metabolic component, by maintaining blood pressure and volume or improving by-pass perfusion As by-pass is prolonged over 11\% to 2 hours it is usually necessary to correct a metabolic acidosis by the intravenous use of sodium bicarbonate. The development of metabolic acidosis as perfusion is prolonged is no doubt largely due to the less than physiological tissue perfusion mamtained by the pump oxygenator. ${ }^{4}$ For these reasons our study has been of value principally in providing an awareness of the patients' acid-base status and the ability to make early adjustments for dangerous deviations.

Examples of these deviations are shown in the following cases:

(a) The graph of Figure 4 was obtained by following a 3-year-old child under-

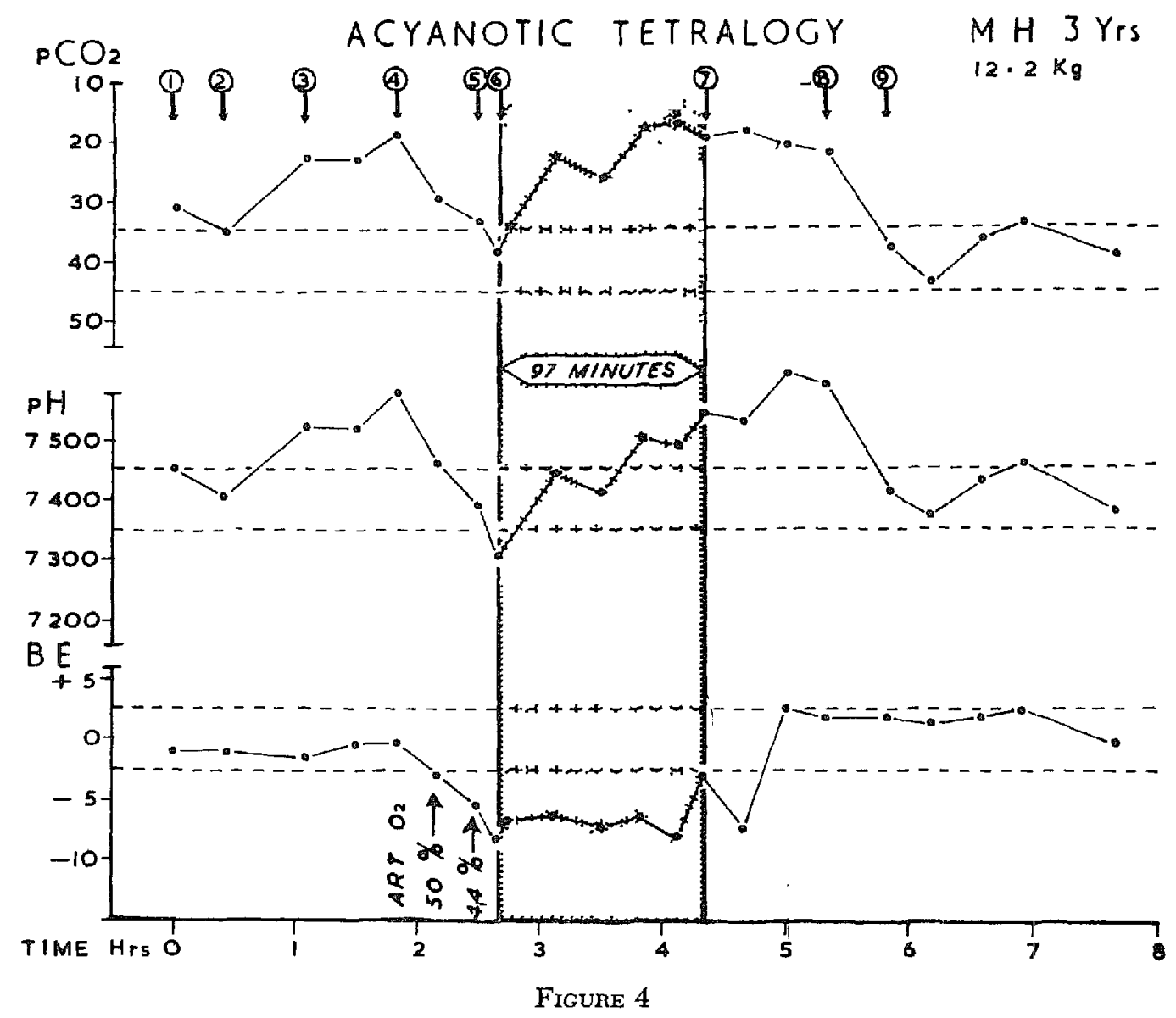


going correction of an acyanotic tetralogy. The graph illustrates one abnormality which occurred just before perfusion when the patient developed a metabolic and respiratory acidosis, ${ }^{5}$ which was attributed to a reversal of his intracardiac shunt due to a fall in systemic pressure. The situation was corrected by use of a vasopressor and the initiation of perfusion.

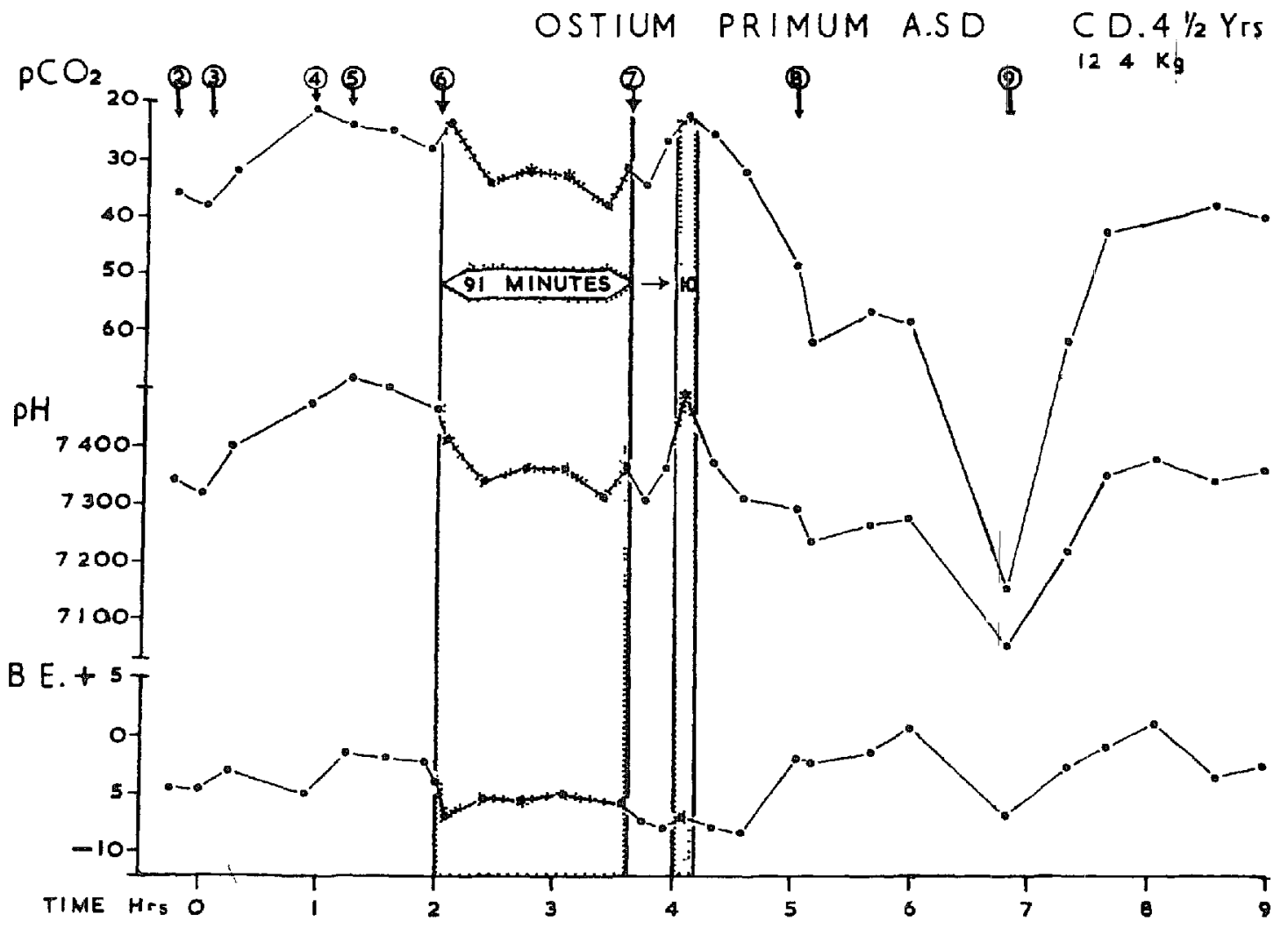

FIGURE 5

(b) The graph of Figure 5 was obtained by following a patient undergoing surgery for correction of an auricular septal defect of the primum type. The first variation noted is the lack of respiratory alkalosis durng the perfusion. This lack can be explained by the jintroduction of $\mathrm{CO}_{2}$ into the incision at a rate of 5 litres per minute during the repair to prevent air entering the left heart with the production of air emboli. The $\mathrm{CO}_{2}$ in the incision is returned to the oxygenator through the surgical suction, producing a respiratory acidosis. The other variation, a marked respiratory acidosis, occurred in the recovery room and was due to improper use of a mechanical respirator, which when corrected allowed the acid-base status to return to normal.

(c) The graph in Figure 6 was obtained by following a patient undergoing surgery for mitral stenosis with some degree of regurgitation. The patient presented with a marked compensated respiratory acidosis and also demonstrated some deficiency in diffusion of $\mathrm{CO}_{2}$ during the anaesthesia, no doubt due to his long-standing cardiac failure. Following correction of the stenosis he remained for some time in a state of respiratory acidosis. There was gradual improvement 


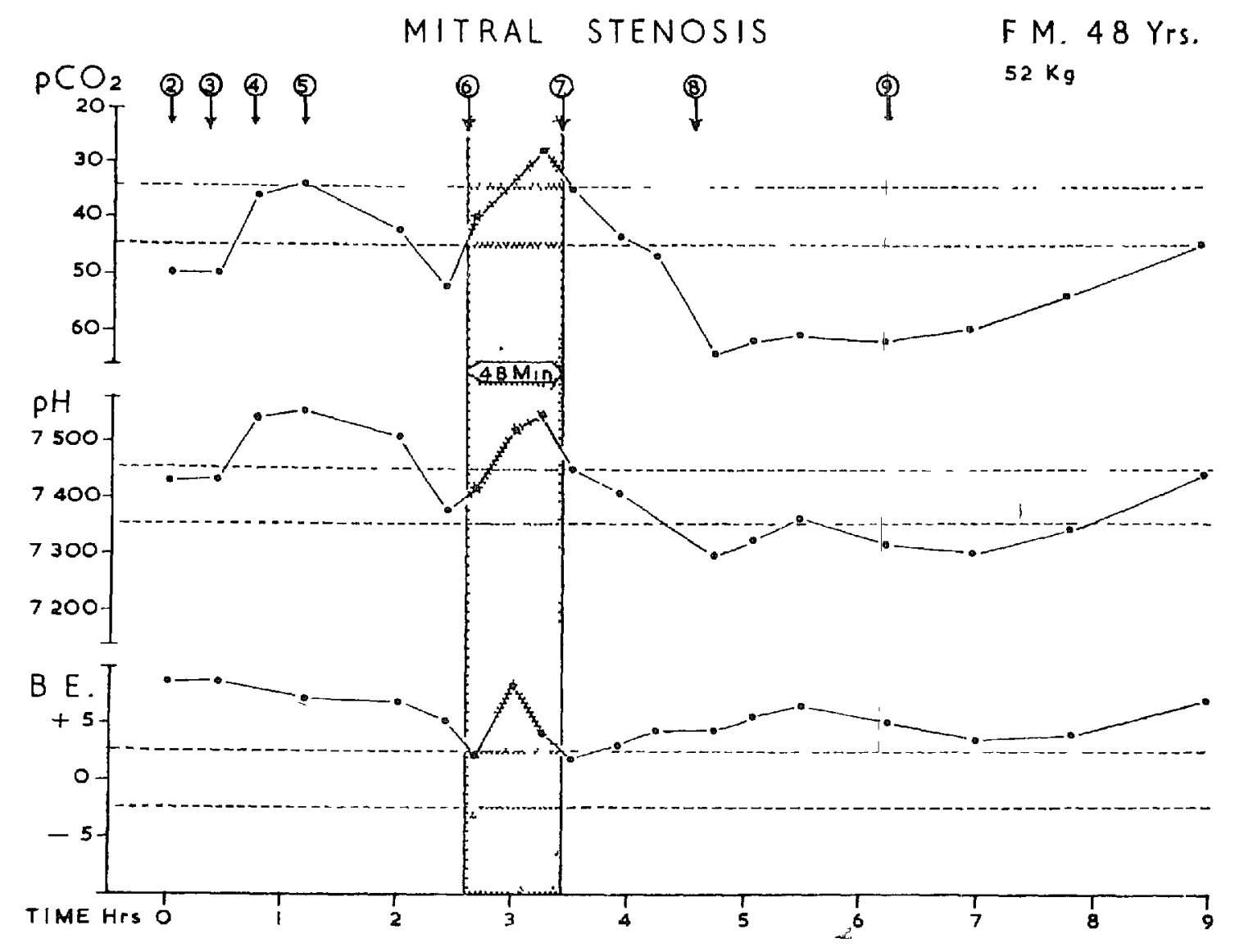

Figtre 6

due to ventilatory assistance by a respirator and, no doubt in part, due to improving pulmonary function. These are but a few of the deviations noted during anaesthesia, surgery, and by-pass, and are presented to show some of the varied causes which produced metabolic and respiratory acid-base changes in our series.

\section{Discussion}

To follow all open-heart procedures in this comprehensive manner in the future is perhaps too time-consuming. However, having established the normal response, periodic checks throughout the procedure have allowed us to be aware of changes and to correct them in order to have our patients arrive in the recovery room with normal acid-base balance.

It is in the postoperative period that we have tound our studies most useful and to which we wish to direct our efforts more specifically in the future. By following the patients closely until acid-base stability is reached we are aware more quickly of some of the common postoperative complications. These may be divided into two groups: (a) respiratory complications due to pneumothorax, haemothorax, atelectasis, or reduced pulmonary function due to inadequate ventilation or poor gaseous diffusion; $(b)$ cardiovascular complications due to low blood volume, cardiac failure, tamponade, or low cardiac output due to 
mechanical interference such as occurs with a large right ventriculotomy, the insertion of a right ventricular out-flow patch, or from valvular deficiencies. It is our custom to leave a cannula in the radial artery for ease of sampling during the first 1 to 4 hours in the recovery room.

There are two groups of patients which benefit particularly from a more careful postoperative control. (1) The patient in the infant age group, that is under two years of age, requiring corrective surgery. Experience has shown that these patients do poorly because of blood volume difficulties, of the relatively large ventriculotomy required in a small heart, and of haemodynamic and respiratory problems postoperatively. The ability to estimate rapidly the degree of respiratory or metabolic acid-base changes in these patients has allowed for earlier recognition and treatment of postoperative complications previously enumerated. (2) Patients undergoing aortic valvular plication or replacement for calcific aortic stenosis or regurgitation. The operative mortality in these patients is high. However, if valvular function can be restored by the surgeon, the postoperative period is particularly hazardous owing to the usually long operative period and the associated left ventricular disease.

\section{SUMMaRY}

So-called normal respiratory and metabolic acid-base responses to anaesthesia, surgery, and by-pass in open-heart patients has been described. Careful monitoring of these parameters allows for early correction of deviations. The immediate postoperative management of infants and patients with aortic valvular disease may be improved by these means.

\section{RÉsumé}

Nous avons soigneusement surveillé 150 cas de chirurgie à cour ouvert au coưrs de l'anesthésie, de la chirurgie et de la circulation extra-corporelle. L'équilibre acide-base a été établi en faisant des déterminations fréquentes du $\mathrm{pH}$, du $\mathrm{pCO}_{2}$ et de l'excès de carbonates selon le nomogramme Astrup. Nous avons utilisé l'appareil micro-Astrup au cours de cette étude à cause de la petite quantité de sang qu'il requiert, à cause de son mécanisme compensaleur de la température et à cause de la rapidité avec laquelle on peut faire les analyses. Ces déterminations sont importantes dans la salle d'opération parce qu'elles renseignent sur la déviation de la normale et elles permettent de corriger les écarts et d'amener à la salle de réveil des malades avec un équilibre acide-base normal.

La où cette étude s'est avérée la plus significative, c'est dans la salle de réveil, particulièrement au cours de la première ou des quatre premières heures, alors que des déterminations répétées acide-base métabolique et respiratoire laissent prévoir l'apparition de complications respiratoires ou cardiovasculaires.

La surveillance étroite des petits enfants soumis à la chirurgie à coeur ouvert et des malades subissant de la chirurgie pour valvules aortiques en ce qui concerne les modifications de l'équilibre acide-base prend toute son importance au cours des premières heures dans la salle de réveil. 


\section{REFERENCES}

1. Randall, H. T., \& Roberts, K. E. The Significance and Treatment of Acidosis and Alkalosis in Surgical Patients. Surgical Cl. N.A., 315-333 (April, 1956).

2. Boyle, J. P.; Wertzman, J.; \& Berne, C. J. Indications for Measurement of Arterial pH. Amer. J. Surg. 100: 346-353 (1960).

3. DeWall, R. A.; Warden, H. E.; Melby, J. C.; Mrnot, H.; Varco, R. L.; \& Liflehei, C. W. Physiologic Responses during Total Body Perfusion with a Pump-Oxygenator. J.A.M.A. 165: 1788-1792 (1957).

4. Paneth, M.; Sellers, R.; Gott, V. L.; Weirich, W. L.; Allen, P.; Read, R. C.; \& Lillehei, C. W. Physiologic Studies upon Prolonged Cardiopulnonary By-pass with the Pump-Oxygenator with Particular Reference to (1) Acid-Base Balance, (2) Siphon Caval Drainage. J. Thoracic Surg. 34: 570-579 (1957).

5. DeWall, R. A.; Long, D. M.; Gemanll, B. S.; \& Lilleher, C. W. Certain Blood Changes in Patients Undergoing Extracorporeal Circulation. J. Thoracic Surg. 37: 325333 (1959).

6. Lillehei, C. W.; Warden, H. E.; DeWall, R. A.; Stanley, P.; \& Varco, R. L. CardioPulmonary By-pass in Surgical Treatment of Congenital or Acquired Cardiac Disease. A.M.A. Arch. Surg. 75: 928-945 (1957).

7. Gross, R. E.; Sauvage, L. R.; Pontius, R. C.; \& Watkins, E. JR. Experimental and Clinical Studies of a Siphon-Filling Disk Oxygenator System for Complete Cardiopulmonary By-pass. Ann. Surg. 151: 285-302 (1960).

8. Anderson, O. S.; Engel, K.; Jorgensen, K.; \& Astrup, P. A Micro Method for Determination of $\mathrm{pH}$, Carbon Dioxide Tension, Base Excess and Standard Bicarbonate in Capillary Blood. Scandinav. J. Clin. \& Lab. Invest. 12: 172-175 (1960).

9. MeliemgaArd, K., \& Astrup, P. The Quantutative Determination of Surplus Amounts of Acid or Base in the Human Blood. Scandinav. J. Clin. \& Lab. Invest. 12: 187-199 (1960).

10. Astrup, P.; Jongensen, K.; Anderson, O. S.; \& Enget, K. The Acid-Base Metabolism, a New Approach. Lancet i: 1035-1038 (1960).

11. Knunsen, E. J., \& Hansen, P. Carbon Dioxide Tensions in Non-arteriologized Capillary and Arterial Blood during Anaesthesia. Acta. Anaes. Scandinav. 6: 29-35 (1962).

12. Anderson, O. S., \& Enget, K. A New Acid-Base Nomogram. Scandinav. J. Clin. \& Lab. Invest. 12: 177-186 (1960).

13. Caliaghan, J. C.; Fraser, R. S.; Dvorkin, J., \& Stewart, A. C. The Acid-Base Aspects of Extra Corporeal Circulation. In Extracorporeal Circulation, 1st ed., p. 149. Springfield, Ill.: Charles C. Thomas (1958). 